\title{
URUGUAY 2015: LOS DESAFÍOS DE GOBERNAR POR IZQUIERDA CUANDO LA ECONOMÍA SE CONTRAE
}

\author{
Uruguay 2015: The Challenges of the Left Government under Negative \\ Economic Perspectives
}

\section{VERÓNICA PÉREZ}

Universidad Torcuato Di Tella

\section{RAFAEL PIÑEIRO RODRÍGUEZ}

Universidad Católica del Uruguay

\section{RESUMEN}

Este artículo analiza el primer año de gestión del tercer gobierno consecutivo del Frente Amplio en Uruguay. El repaso de los principales eventos políticos ocurridos durante el año da cuenta de las dificultades que tienen los partidos como el Frente Amplio para gobernar bajo mandatos de izquierda cuando las perspectivas económicas son negativas. La pérdida de dinamismo económico, las presiones inflacionarias, el deterioro de las cuentas públicas y la concomitante reducción del espacio fiscal, catalizaron los conflictos entre el gobierno y sus bases sociales. El deterioro del frente externo ha puesto en cuestión a uno de los gobiernos más exitosos de la región en los últimos diez años que, ante un escenario desconocido, intenta navegar entre la consolidación de su agenda distributiva y de crecimiento.

Palabras clave: Uruguay, Frente Amplio, elecciones, economía política.

\begin{abstract}
This article analyzes the first year of Frente Amplio's third government in Uruguay. The main political events during 2015 show the difficulties that leftist parties in government have when governing under negative economic perspectives. A decline in economic dynamism, combined with inflationary pressures and fiscal deterioration, boosted conflicts between the government and their social bases. Facing a worsening economic scenario, one of the most successful Latin American governments in the last ten years tries to navigate between the consolidation of its redistributive agenda and its political needs to secure economic growth.
\end{abstract}

Key words: Uruguay, Frente Amplio, elections, political economy. 


\section{INTRODUCCIÓN}

El año 2015 fue el primero del tercer gobierno consecutivo del Frente Amplio (FA) en Uruguay, un partido programático de centroizquierda. Pese a que la mayoría de las encuestas de opinión pública pronosticaban un escenario electoral complicado para la izquierda en las elecciones nacionales de 2014, el FA volvió a ganar con mayorías parlamentarias como en las dos elecciones anteriores (2004 y 2009). Como en la elección de 2004 Tabaré Vázquez volvió a ser electo Presidente.

La literatura comparada relativa a nuevas izquierdas en América Latina ha caracterizado a los gobiernos del FA en el grupo de gobiernos de izquierda moderada (Castañeda, 2006; Weyland, 2009; Flores-Macías, 2010; Levitsky y Roberts, 2011; Lanzaro, 2011). Estas son izquierdas que no desafían los parámetros de la democracia liberal y que cuando llegan al gobierno persiguen objetivos redistributivos, pero realizan una gestión "ortodoxa" de la economía. ${ }^{1}$ Tal característica no impidió que los dos gobiernos anteriores del Frente Amplio avanzaran en reformas laborales, sociales e impositivas con beneficios distributivos hacia las clases populares y los sectores medios. Al final de una década Uruguay se distingue en la región por el uso de mecanismos de negociación centralizada y tripartita de los salarios - principal instrumento en la mejora de los ingresos de los trabajadores-, por la aprobación de más de 40 leyes que consagran y extienden derechos laborales, incluso a sectores antes excluidos como los trabajadores rurales y las empleadas domésticas (Senatore y Méndez, 2011), así como por los avances hacia mayores niveles de universalismo de la matriz de protección social, sobre todo en las áreas de salud y en las transferencias hacia las familias (Pribble y Huber, 2011; Pribble, 2013).

Las reformas procesadas durante los dos primeros gobiernos del FA se produjeron en el marco de un contexto económico favorable, signado por un commodity boom. Esto permitió que Uruguay, un país exportador de alimentos y materias primas, creciera durante una década, a tasas inusuales para su promedio histórico. Sin embargo, estas circunstancias comenzaron a cambiar en 2014 afectando las perspectivas de crecimiento del país. En consecuencia, el tercer gobierno del FA asume en un contexto de desaceleración económica donde debe enfrentar el dilema que la literatura comparada sobre América Latina señala para los gobiernos de izquierda; por un lado, debe responder a las demandas por mayor distribución de sus votantes y en espacial los sindicatos, su principal base social, y por otro, mantener los equilibrios macroeconómicos y el crecimiento (Murillo, Oliveros y Vaishnav, 2011; Campello, 2014). Mayores niveles de distribución requieren aumentar la carga impositiva y mantener los niveles de crecimiento salarial. Estas políticas reducen la rentabilidad del capital y desincentivan la inversión, en particular la extranjera. En economías pequeñas y dependientes como la uruguaya, la reducción de los niveles de

En el mismo grupo de Uruguay están el gobierno del PT en Brasil y el liderazgo del PS en los gobiernos de la Concertación en Chile. En el grupo de gobiernos de izquierdas radicales estarían el chavismo en Venezuela, el gobierno del MAS en Bolivia y el de Rafael Correa en Ecuador. Como un caso híbrido entre los gobiernos de nueva izquierda moderados y radicales estarían los gobiernos del kirchnerismo en Argentina. 
inversión se traduce rápidamente en disminución del producto, aumento del desempleo y caída de la recaudación.

Este artículo analiza los principales eventos políticos ocurridos durante el 2015 en Uruguay y se inserta en la discusión de la literatura en política comparada que pone énfasis en los constreñimientos que tienen los ciclos económicos contractivos para gobernar por izquierda en América Latina. En la siguiente sección se analizan los resultados del ciclo electoral 2014/2015. En el tercer apartado se describe el panorama de desaceleración económica que enfrenta al tercer gobierno del FA. En la cuarta y quinta secciones se describe la formación de gobierno, la performance del Ejecutivo en su primer año de gestión y el funcionamiento del Parlamento. En la sexta, se analiza la relación del gobierno con los actores sociales y se plantean los desafíos de economía política que enfrenta. Por último, se presentan algunas conclusiones.

\section{CICLO ELECTORAL 2014/2015}

Los resultados de la elección nacional (primera vuelta presidencial y elección de diputados y senadores) del 27 de octubre de 2014 en Uruguay marcaron la consolidación de un patrón de continuidad en el sistema de partidos uruguayo. La evolución electoral en las últimas tres elecciones (2004, 2009 y 2014) muestran lo que Buquet y Piñeiro (2014) denominaron "nuevo equilibrio" en el sistema de partidos uruguayo. Desde la elección de 1971 hasta la de 2004, como lo señalan Queirolo y González (2000), los resultados electorales presentaron un crecimiento sistemático del Frente Amplio (FA) y una caída concomitante de los partidos tradicionales (Partido Colorado (PC) y Partido Nacional $(\mathrm{PN})$ ). El bipartidismo tradicional (PN y PC) fue cambiando de manera gradual hasta consolidar, a partir de la elección de 2004, un sistema tripartidista. ${ }^{2}$

Los niveles de polarización ideológica del sistema de partidos uruguayo son relativamente altos en el contexto latinoamericano (Moraes, 2015). El realineamiento electoral que se procesó en Uruguay entre 1971 y 2004 no se debió a cambios en la autoidentificación ideológica de los ciudadanos (Canzani, 2000). ${ }^{3}$ Por el contrario, fueron los partidos los que terminaron alterando sus posiciones políticas y captando diferentes sectores del electorado. Por un lado, el FA procesó una moderación (Yaffé, 2005; Lorenzoni y Pérez, 2013) y por otro los partidos tradicionales perdieron poder de captación de electores

2 La pauta de evolución del sistema de partidos uruguayo tiende a reflejar lo que Roberts (2014) define como un realineamiento paulatino que reestructura al sistema de partidos en términos programáticos. La posición que cada partido sustentó frente al programa de reformas económicas promercado de los noventa, agrupó a los viejos partidos tradicionales en la centroderecha y al FA en la centroizquierda. Desde la elección de 2004, el electorado se ha dividido por mitades entre el centro derecha y el centro izquierda, y ha consagrado en cada elección sendas mayorías parlamentarias en ambas Cámaras para el FA. Esto ha convertido a Uruguay, como lo señala Lanzaro (2015), en un sistema de partidos predominante.

3 El aumento de votos de partidos de izquierda sin corrimiento a la izquierda del electorado no es exclusivo de Uruguay; Queirolo (2013), al estudiar el giro a la izquierda en América Latina, constata que este no obedece a cambios en la autoidentificación ideológica de los electorados del continente, sino al rechazo a la performance de los partidos de centroderecha en el gobierno. 
Gráfico 1: Evolución de los resultados electorales (\%) en elecciones nacionales 1971-2014.

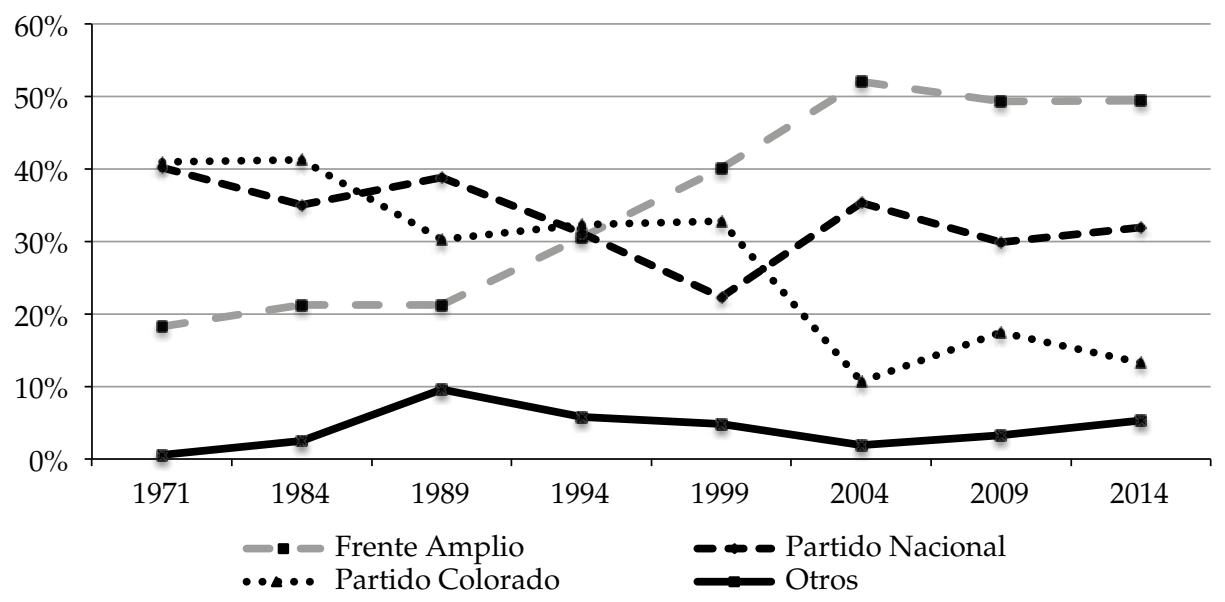

Fuente: Elaboración a base de datos de la Corte Electoral.

de centro. En consecuencia, la moderación del FA y su éxito electoral no supuso, en un escenario de permanencia en la autoidentificación ideológica del electorado, la mimetización de la oferta partidaria en posiciones de centro.

Las acciones del FA en el primer gobierno de Tabaré Vázquez (2005-2010) y en el de José Mujica (2010-2015) no pueden catalogarse como de continuidad respecto de las administraciones anteriores. Si bien los dos primeros gobiernos frenteamplistas se preocuparon, como los de los partidos tradicionales antes, de mantener los equilibrios macroeconómicos, en particular de mantener contenida la inflación, lejos estuvieron de mostrar continuidades en las más diversas áreas de política. Buena parte de estos cambios pueden identificarse como políticas asociadas a posiciones de izquierda o en sentido más lato a posiciones "progresistas". A modo de ejemplo, el primer gobierno de Tabaré Vázquez aumentó significativamente el gasto social (Caetano y De Armas, 2011); instauró un programa de transferencias condicionadas para atender la emergencia social que luego evolucionó en una política de transferencias a las familias con rasgos más universalistas (Pribble, 2013); reinstauró la negociación colectiva por rama de actividad extendiendo el mecanismo a sectores antes excluidos como los trabajadores rurales y las empleadas domésticas y sancionó casi 40 leyes concernientes a derechos laborales colectivos (Senatore y Méndez, 2011); realizó una reforma tributaria que supuso un aumento de la progresividad del sistema por medio del impuesto a la renta; e implementó un seguro nacional integrado de salud que dio cobertura de salud a sectores no cubiertos hasta ese entonces. El gobierno de José Mujica dio continuidad a estas políticas, pero además avanzó en "políticas libertarias", entre las que se destacan la despenalización de la interrupción voluntaria del embarazo, la despenalización del autocultivo de cannabis y la regulación de su venta, y de reconocimiento legal del matrimonio de personas del mismo sexo (Bidegain, 2013; López Cariboni y Moraes, 2014). 
La continuidad aparente de los resultados electorales esconde transformaciones en el comportamiento electoral en Uruguay. Al igual que en otros países de América Latina gobernados por la izquierda, los alineamientos electorales comienzan a reflejar algo extraño para la región, el voto de clase (Handlin, 2012; Madrid, 2012). Es decir, a pesar de la estabilidad de los resultados, estos no son producto exclusivamente de la permanencia de las preferencias electorales de los uruguayos, sino de cambios en ellas. A partir de datos de encuestas, López Cariboni y Queirolo (2015) muestran la aparición de voto de clase en Uruguay. ${ }^{4}$ Asimismo, se registraron cambios en la composición del voto frenteamplista. Por un lado, creció en el interior del país y se redujo en Montevideo, la capital. ${ }^{5}$ Por otro, los sectores más radicales y en particular el del expresidente José Mujica y el del actual vicepresidente Raúl Sendic aumentaron su caudal de votos y representación parlamentaria en relación al sector más moderado liderado por el ex vicepresidente y actual ministro de economía Danilo Astori. 6 El Movimiento de Participación Popular (sector de José Mujica) y Compromiso Frenteamplista (Raúl Sendic) controlan 9 de los 16 senadores (sumando al vicepresidente) y 31 de los 50 diputados del FA (56 y 62\% de cada Cámara respectivamente).

Dentro de los partidos tradicionales, el PC redujo su votación respecto de 2009 de 17,5\% a 13,3\% y el PN solo aumentó dos puntos, de $29,9 \%$ en 2009 a 31,9\% en 2014. A pesar de cierta euforia y expectativa que los líderes de ambos partidos vivieron durante la campaña electoral en función de resultados de encuestas que les auguraban una mejor performance, en conjunto terminaron con un resultado un poco peor que el de hace cinco años. En el PN, el triunfo en la primaria de junio de 2014 de Luis Lacalle Pou (hijo del expresidente Luis A. Lacalle (1990-1995) y la imagen que proyectó en su campaña, representó la consolidación de un nuevo liderazgo con un estilo renovado, más moderno, similar al de otras expresiones de centroderecha en América Latina (en particular la del PRO de Mauricio Macri en Argentina).

El ciclo electoral 2014-2015 cerró con las elecciones departamentales y locales de mayo de 2015. En ellas se eligieron intendentes y juntas departamentales en cada uno de los 19 departamentos, y alcaldes y concejos municipales en los 112 municipios del país. Estas elecciones se realizan dos meses después de la asunción del nuevo Presidente por lo que terminan de definir el escenario político en el que el nuevo gobierno se va a desenvolver.

Las elecciones departamentales de 2015 mostraron por primera vez una experiencia de coordinación expresa entre los partidos tradicionales (PN y PC) para la elección de

4 López Cariboni y Queirolo (2015) estudian el comportamiento electoral en Uruguay utilizando datos de encuestas electorales entre 1989 y 2014. Sus análisis muestran cómo los modelos de voto de clase explican de mejor manera el voto en las últimas elecciones que los modelos tradicionales de voto económico (los que funcionan mejor para elecciones previas a 2009).

5 Mientras que en 2009 el voto montevideano representaba el 47,2\% de los votos del FA, en 2014 fue el 43,8\% (la baja en este porcentaje es producto tanto de un aumento en términos absolutos de los votos del FA en el interior del país como de una caída de votos en Montevideo).

6 El Movimiento de Participación Popular (José Mujica) y Compromiso Frenteamplista (Raúl Sendic) obtuvieron sumados el 45,3 \% de los votos del FA, mientras que Asamblea Uruguay (Danilo Astori) recogió el 18,1\%. En 2009 el Movimiento de Participación Popular y Compromiso Frenteamplista habían obtenido el 34,8\%, mientras que Asamblea Uruguay había obtenido el 27,19\%. 
Montevideo (la principal circunscripción del país). Estimulados por el sistema de mayoría simple para la elección de intendentes, durante 2013 dirigentes de los partidos tradicionales comenzaron a esbozar el Partido de la Concertación (unión del PN y PC). ${ }^{7}$ Como señalan López Cariboni y Moraes (2014), esta estrategia fue impulsada por cierta expectativa de parte de dirigentes de ambos partidos de poder arrebatar el gobierno departamental de Montevideo (la principal circunscripción en disputa) al FA. Los resultados de la elección de 2010 (donde el FA bajó significativamente su nivel de votación) y las evaluaciones de gestión negativas de la en ese entonces intendenta frenteamplista Ana Olivera, hicieron pensar a los dirigentes de ambos partidos que esto era posible.

El Partido de la Concertación presentó tres candidatos, ${ }^{8}$ uno del PC (Ricardo Rachetti), uno del Partido Nacional (Álvaro Garcé) y un independiente vinculado al PC (Edgardo Novick). Más allá del esfuerzo del PC y el PN por coordinar en un único partido, como sucede desde la elección del 1989, el FA volvió a ganar la Intendencia de Montevideo por más de 14 puntos (el FA obtuvo el 55,7\% mientras que la Concertación alcanzó el $41,6 \%$ ). Pero la mayor sorpresa de esa elección no fue el triunfo del FA, que nunca estuvo en cuestión durante toda la campaña, sino que dentro del Partido de la Concertación el candidato independiente Edgardo Novick obtuviera la mayoría abrumadora de votos. ${ }^{9}$ En consecuencia, la estrategia del PN y PC no solo fue ineficiente para disputarle la Intendencia de Montevideo al FA, sino que también habilitó el surgimiento de una personalidad que, por fuera de ambos partidos, logró capturar por sobre la mayoría de los votos de centroderecha en la capital del país. A partir de una campaña centrada en su capacidad de gestión y en una supuesta neutralidad ideológica, Edgardo Novick se transformó en algo inusitado para Uruguay, una figura política que no pertenece a ninguno de los tres principales partidos.

En términos generales, los resultados de las elecciones departamentales mostraron un panorama similar al de hace cinco años. El FA retuvo las intendencias de Montevideo, Canelones (la primera y segunda circunscripción en orden de importancia) y Rocha, perdió las de Maldonado (la tercera más importante del país) y la de Artigas, recuperó las de Salto y Paysandú y ganó por primera vez la de Río Negro. El PN recuperó Artigas y Maldonado y perdió Paysandú y Río Negro. Por último, el PC que solo tenía dos intendencias, Salto y Rivera, perdió Salto y retuvo Rivera. Es difícil pensar en avances o retrocesos de algún partido en términos de su domino territorial, salvo en el caso del PC donde la pérdida de la Intendencia de Salto lo deja como en la peor elección de su historia (2005) solo con la Intendencia de Rivera.

El ciclo electoral 2014-2015, como el ciclo de elecciones anterior, muestra continuidades en varias dimensiones: 1. el FA retiene la mayoría absoluta en ambas Cámaras legislativas

$7 \quad$ La presentación del Partido de la Concertación (alianza entre el PC y el PN) supuso que este partido tuviera que presentarse a las elecciones internas de junio de 2014. Quienes figuraron en sus listas a la convención nacional y departamental del nuevo partido no pudieron ser candidatos en las elecciones nacionales ni por el PC ni por el PN.

8 En las elecciones para intendente los partidos pueden presentar hasta tres candidatos. Bajo el sistema de doble voto simultáneo resulta electo el candidato más votado dentro del partido más votado.

9 Novick obtuvo el 63,4\% de los votos, frente a 31,3\% del candidato del PN y solo 4,7\% del candidato del PC. 
de manera ajustada, 2. el PN se consolida como el principal partido de la oposición sobre el PC, 3. en términos territoriales el PN sigue dominando la mayor cantidad de intendencias y el FA mantiene los gobiernos de las dos principales circunscripciones (Montevideo y Canelones). Los cambios, dentro de estas líneas de continuidad, se pueden resumir en: 1. el crecimiento en votos y en particular en bancas de los sectores más radicales, o al menos más a la izquierda del FA, en detrimento de los más moderados, 2 . la renovación en el liderazgo de la oposición, encarnada en el nuevo líder del PN Luis Lacalle Pou y en el liderazgo emergente de un empresario por fuera de las estructuras partidarias, Edgardo Novik; 3. la aparición de estrategias de coordinación electoral entre el PC y el PN.

Respecto del escenario político surgido del ciclo electoral 2004-2005, el que determinó el inicio del primer gobierno de Tabaré Vázquez (2005-2010), el actual, si bien no muy diferente, presenta algunos desafíos adicionales. En particular, Vázquez debe lidiar con un contingente legislativo donde el sector liderado por el expresidente José Mujica aparece reforzado. En la actualidad, la bancada legislativa FA está bastante más a la izquierda del Presidente que lo que estuvo en los dos gobiernos anteriores. Asimismo, la oposición, a pesar de haber sufrido una nueva derrota, logró mostrar renovación y dar la apariencia, al menos durante la campaña electoral, de que era capaz de arrebatarle el gobierno nacional al FA.

\section{PANORAMA ECONÓMICO}

El escenario internacional y regional de la economía uruguaya, en particular la caída de la economía brasileña y la desaceleración china, pusieron en alerta al nuevo gobierno. Si bien la baja de los precios de los commodities agrícolas (base de la economía uruguaya) no fue tan drástica como la de los minerales (en especial el petróleo), de cualquier manera contribuyen a la generación de expectativas negativas respecto del futuro de la economía tanto en los agentes económicos como en el gobierno. A un frente externo no tan favorable como el de hace años, se suma la pérdida de dinamismo de la demanda interna asociada a la caída del consumo interno y a la formación bruta de capital (BCU 2015). El panorama que delineaban López Cariboni y Moraes (2014) al final de 2013 respecto de la dificultad para que el mercado doméstico sea capaz de mantener el crecimiento sin provocar inflación, es ahora más acuciante. Uruguay seguirá creciendo, pero a un ritmo mucho menor al de los años anteriores (entre 0,5 y $1 \%$ rondará la cifra para 2015).

Durante 2015, la caída del empleo y la baja en la tasa de actividad produjo también un aumento del desempleo que en el año promedió el 7,5\% (cifra que, aunque alta para los últimos 5 años, es baja en términos históricos). Según BCU (2015), la baja de la tasa de actividad y el aumento del desempleo no repercutieron en la calidad del empleo. Entre los ocupados siguieron mejorando los índices de formalización (de 25,2\% en octubre de 2014 a 23,7\% en el mismo mes de 2015). Por otro lado, los niveles medios de ingreso se mantuvieron estables, luego de varios años de crecimiento. 
Gráfico 2. Evolución de la tasa de crecimiento, del desempleo, del déficit fiscal y de la inflación en Uruguay 2006-2015
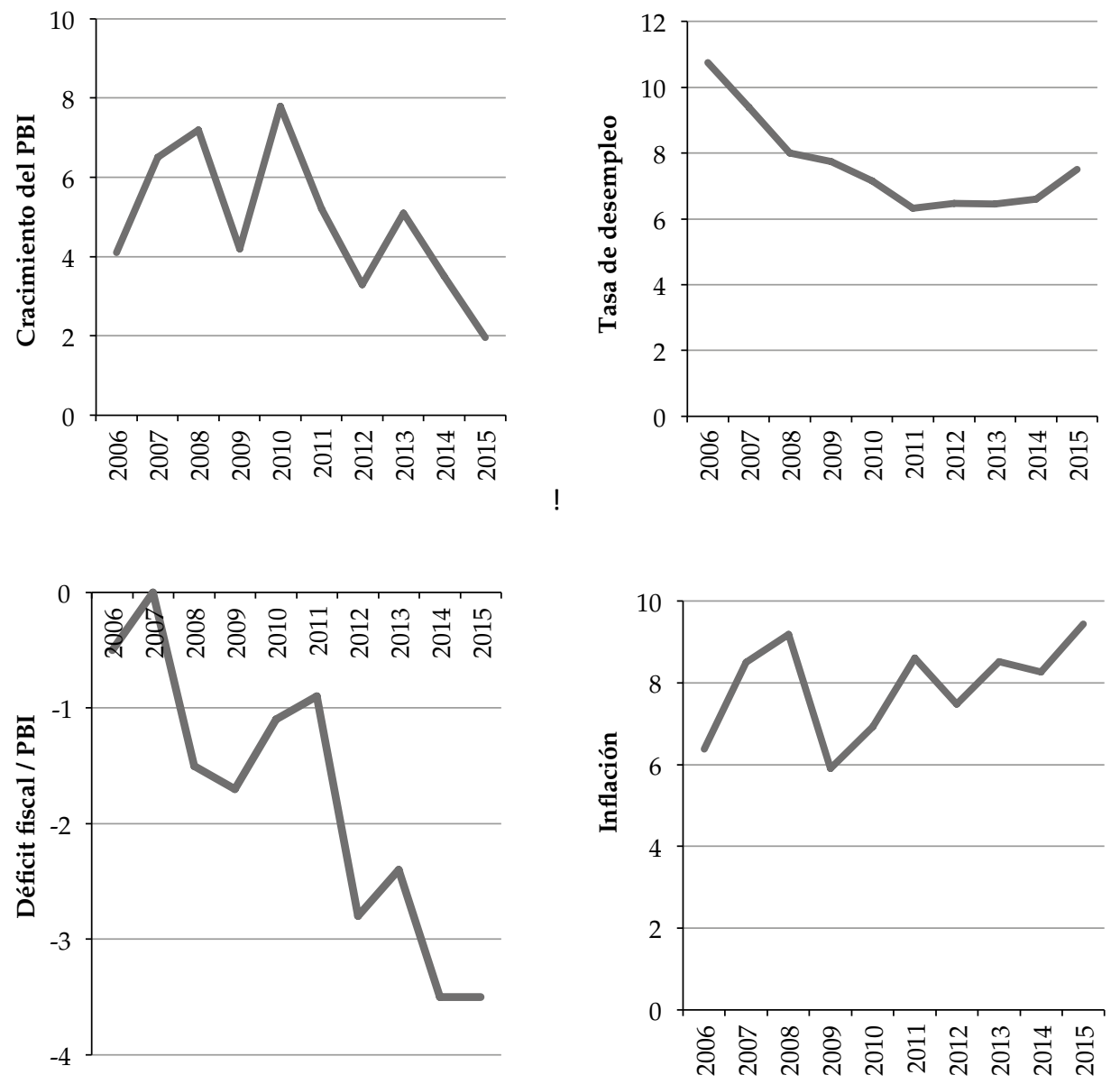

Fuente: Elaboración a base de datos del Banco Central del Uruguay, del Ministerio de Economía y Finanzas y del Instituto Nacional de Estadística.

En este ambiente de desaceleración económica, las presiones inflacionarias cada vez fueron mayores. En diciembre de 2015 la tasa de inflación anual alcanzó el 9,44\%, cifra que está por encima del rango meta (3\%-7\%) establecido por la autoridad monetaria. La depreciación significativa del peso frente al dólar en $2015^{10}$ también ha generado presiones sobre los precios, en particular de los bienes transables. Desde mediados de 2013 la inflación pasó a ser una de las obsesiones del gobierno que ha buscado controlarla con

10 La depreciación del peso frente al dólar fue la más grande desde la devaluación de 2002 y ha permitido recuperar competitividad respecto del mundo, pero no logró hacer lo mismo en términos regionales debido a las devaluaciones de Brasil y Argentina (CINVE, 2015). 
medidas ortodoxas de política monetaria y heterodoxas como los acuerdos de precios y el manejo de precios administrados (como por ejemplo el servicio de energía eléctrica).

Unido a la inflación y relacionado con ella, es apreciable el deterioro fiscal que se ha producido en los últimos dos años. El déficit en 2015 fue, al igual que en 2014, de 3,5\% del PBI. El nivel de deuda neta en relación con el PBI es bajo (25\%), lo que hace sostenible en el corto plazo déficits fiscales de esta magnitud. Sin embargo, el deterioro de los resultados del sector público también se erige como un límite sobre las posibilidades de financiamiento de políticas en un contexto de desaceleración económica.

En 2005 Tabaré Vázquez iniciaba su gobierno en un país que salía de una de las mayores crisis económicas y financieras de su historia (Rosenblatt, 2006). Su desafío, y el del primer gobierno del FA, era la consolidación de la recuperación económica y la atención a los efectos sociales de la crisis, lo que se llamó atención a la "emergencia social". Diez años más tarde, al inicio de su segundo gobierno y del tercer gobierno consecutivo del FA, la coyuntura económica no parece ser menos desafiante. Aunque la situación financiera del país ha dejado de ser un tema, los magros resultados fiscales heredados del gobierno de José Mujica, las presiones inflacionarias y la desaceleración de la economía, le plantearon durante 2015 y le continuarán planteando en los próximos años el reto de consolidar transformaciones en un marco de severas restricciones fiscales.

\section{PODER EJECUTIVO}

\section{Conformación del gabinete}

Al igual que en los dos gobiernos anteriores, el gabinete de Tabaré Vázquez es partido mayoritario, hecho que no es de extrañar en un gobierno que cuenta con mayorías propias en el Parlamento. No obstante, la lógica con la que Vázquez armó su primer gabinete en el tercer gobierno del FA se diferencia de los procedimientos utilizados por él mismo en su primer gobierno (2005-2010) y por José Mujica (2010-2015).

En su primer gobierno, Vázquez conformó el gabinete con casi la totalidad de los líderes de las fracciones del Frente Amplio, estrategia con la que intentó generar equilibrios en la interna del partido de gobierno (Chasquetti, 2007), aun cuando no se respetara la proporcionalidad respecto del peso parlamentario de las fracciones del FA. Por su parte, el primer gabinete de Mujica tuvo una lógica de conformación proporcional al peso de las fracciones del partido en el Legislativo, debido a que Mujica no era el líder del partido -como en su momento lo era Vázquez-, sino el líder de una fracción. Según Buquet y Luján (2011), esta forma de conformar su equipo de gobierno le permitió reflejar la composición de su bancada parlamentaria. En cambio, en las designaciones realizadas por Tabaré Vázquez el 1 de marzo de 2015 parece haber primado más el criterio de cercanía personal de los ministros/as con la figura del Presidente.

La Tabla 1 muestra el peso de las fracciones más relevantes del FA en el gabinete (solo titulares) designado por Vázquez al asumir su segundo mandato, así como el peso de 
esas fracciones en el Parlamento. Como se observa en la Tabla existe una desproporción en el peso de algunas fracciones en el gabinete. El MPP (la fracción más grande del ala "radical" del FA) se encuentra subrepresentada y FLS (la fracción más grande de la llamada ala "moderada") sobrerrepresentado en el gabinete. Mientras el MPP es el sector con mayor cantidad de bancas $(47 \%)$ tiene la misma cantidad de ministros que el FLS que aunque es la segunda fracción en importancia tiene solo $18,2 \%$ de la bancada del FA. También están sobrerrepresentados en el gabinete el Partido Socialista y la Corriente Acción y Pensamiento-Libertad (CAP-L). Esta última fracción no tiene legisladores, pero sí un ministro, Eleuterio Fernández Huidobro en el Ministerio de Defensa. En el gabinete de Vázquez también destaca el peso de los "independientes", es decir, ministros/as que siendo frenteamplistas no pertenecen a ningún sector del partido: son la minoría mayor con el 28,6\%. Entre las fracciones subrepresentadas en el gabinete se encuentra Compromiso Frenteamplista, sector liderado por el vicepresidente de la República (Raúl Sendic) y Casa Grande, ambos sin presencia en el gabinete. Asimismo, en el gabinete de Tabaré Vázquez no hay, a excepción del ministro de Economía Danilo Astori, ningún líder de fracción.

El gabinete del segundo mandato de Tabaré Vázquez parece estar conformado a base de un tercer criterio (diferente al de proporcionalidad o de líderes de fracción): la integración con personas del círculo de confianza del Presidente. Son los casos de: Álvaro García al frente de la Oficina de Planeamiento y Presupuesto, Marina Arismendi en el Ministerio de Desarrollo Social, María Julia Muñoz en el Ministerio de Educación y Cultura, Víctor Rossi en el Ministerio de Transporte y Obras Públicas, y Rodolfo Nin Novoa en el Ministerio Relaciones Exteriores. Tanto Muñoz como Arismendi y Rossi habían sido ministros/as durante el primer mandato de Vázquez, en tanto Nin Novoa fue su vicepresidente.

Tabla 1. Integración del gabinete en el primer año del segundo gobierno de Tabaré Vázquez*

\begin{tabular}{lccccc}
\hline \multicolumn{1}{c}{ Fracción } & Ministerios & \% Gabinete & Legisladores & \% Legisladores & Diferencia \\
\hline FLS & 3 & 21,4 & 12 & 18,2 & 3,2 \\
MPP & 3 & 21,4 & 31 & 47,0 & $-25,5$ \\
Independientes & 4 & 28,6 & 0 & 0,0 & 28,6 \\
PS & 2 & 14,3 & 6 & 9,1 & 5,2 \\
PCU & 1 & 7,1 & 2 & 3,0 & 4,1 \\
CAP-L & 1 & 7,1 & 0 & 0,0 & 7,1 \\
Lista 711 & 0 & 0,0 & 9 & 13,6 & $-13,6$ \\
Casa Grande & 0 & 0,0 & 3 & 4,5 & $-4,5$ \\
Otros & 0 & 0,0 & 3 & 4,5 & $-4,5$ \\
\hline
\end{tabular}

* Se incluye la Oficina de Planeamiento y Presupuesto (OPP) por tener rango ministerial.

Fuente: elaboración propia a base de datos de las páginas web de Presidencia y del Parlamento uruguayo. 
Más allá de estas diferencias, la línea de continuidad en la conformación de los gabinetes del FA está en el equipo económico. Al igual que en su primer mandato, Tabaré Vázquez volvió a designar a Danilo Astori al frente del Ministerio de Economía y a personas de su misma línea política en las otras agencias estatales que componen el equipo económico (la Oficina de Planeamiento y Presupuesto y el Banco Central). Durante la administración del presidente Mujica, Astori había sido vicepresidente de la República, pero se había reservado la conducción del equipo económico acordando con Mujica que la conducción del Ministerio de Economía y del Banco Central estarían en manos de integrantes del FLS. De este modo, el 1 de marzo de 2016 se cumplirán 11 años en los que la economía uruguaya está dirigida por el ala moderada del Frente Amplio.

Por último, con cinco ministras, el gabinete del segundo mandato de Tabaré Vázquez es el más feminizado en la historia del país $(35,7 \%)$, superando incluso los niveles de feminización de los gabinetes de su primer mandato, donde el porcentaje de ministras se acercó al 30\%. La presencia de mujeres en los gabinetes de Vázquez contrasta así con los gabinetes del resto de los gobiernos posdictadura, donde la presencia femenina fue escasa o nula, incluso en los gabinetes de José Mujica en los que nunca hubo más de dos mujeres a la vez al frente de ministerios.

\section{La agenda del Poder Ejecutivo en el tercer gobierno de izquierda}

Cuando Tabaré Vázquez asumió su segundo mandato era esperable que mantuviera las principales políticas de los dos gobiernos anteriores a la vez que profundizara en algunas de ellas. En este sentido, el 1 de marzo de 2015 Vázquez expuso por cadena nacional los lineamientos de política que catalogó como las "señas de identidad" del tercer gobierno de la izquierda en Uruguay. El Presidente anunció reformas institucionales, políticas de desarrollo de la economía social y aumento del gasto público destinado a la inversión en infraestructura, la ampliación de las prestaciones gratuitas del Sistema Nacional Integrado de Salud, la estabilización del Plan Juntos de emergencia habitacional, y especialmente, para las dos grandes reformas sociales de su nuevo mandato: la creación del Sistema Nacional de Cuidados (SNC) y la reforma educativa.

Vázquez catalogó al SNC -destinado a la atención de las necesidades de cuidado de las personas dependientes, en particular ancianos, personas con discapacidad y niños / as pequeños- como el "buque insignia" de su segunda gestión. La implementación de una política de este tipo implicaría la ampliación de la matriz de protección social uruguaya para cubrir riesgos que las familias uruguayas, en especial las de contextos más vulnerables, no pueden enfrentar por sí solas fruto de las transformaciones sociodemográficas experimentadas por el país en los últimos 30 años.

En el ámbito de las políticas educativas, Tabaré Vázquez anunció que cumpliría con su compromiso de campaña -y principal demanda de los gremios docentes- de llevar al gasto público en educación al 6\% del PBI. Esta meta implicaba un esfuerzo fiscal importante en un contexto de menor dinamismo económico, y era a su vez superador del aumento significativo del presupuesto educativo promovido por los anteriores gobiernos del FA donde el gasto en esta área se había incrementado hasta representar 
el 4,5\% del producto. Pero más allá del aumento presupuestal, el Presidente anunció que su gobierno promovería transformaciones sustantivas que llevarían a "cambiar el ADN de la educación", avanzando en una "educación de calidad" que permitiera abatir los niveles de deserción en la educación media y mejorar los resultados en las pruebas de aprendizaje estandarizadas. Entre las medidas anunciadas Vázquez señaló que se impulsaría un sistema integrado de educación básica de los 3 a los 14 años, centros de enseñanza media a escala más pequeña, cambios en los contenidos de los programas de la enseñanza media y programas de profesionalización de la carrera docente. Asimismo, indicó que se esperaba que para el 2020 el 100\% de los jóvenes de hasta 17 años estuviesen incluidos en el sistema educativo y que el 75\% terminara la enseñanza media. Con estos anuncios Vázquez buscaba no solo contentar a los sindicatos docentes, sino también a la oposición que había hecho de la educación uno de sus dos focos de crítica al gobierno (el otro fue la seguridad), pues pese al significativo aumento del gasto público en esta área no se lograron mejorar los indicadores educativos (López Cariboni y Moraes, 2014).

Por último, siguiendo la línea económica de los dos gobiernos anteriores de la izquierda, Tabaré Vázquez expresó que las políticas de su gobierno se desarrollarían respetando los equilibrios macroeconómicos. Enfatizó que se buscaría controlar el déficit fiscal y la inflación, indicadores que se deterioraron durante la administración de Mujica.

\section{La actividad del Poder Ejecutivo durante 2015: éxitos y fracasos en la promoción de políticas públicas}

Una de las formas de observar la actividad del Poder Ejecutivo y cuánto avanzó en su agenda es analizar su concreción en la producción legislativa. En Uruguay, el Ejecutivo es un actor relevante en la producción de legislación, no solo porque tiene iniciativa legislativa en todos los temas, sino también porque en algunos tiene iniciativa exclusiva (iniciativa privativa). ${ }^{11}$ Estos poderes formales, junto a los poderes informales que devienen del hecho de que, por lo general, los Presidentes uruguayos de la posdictadura han contado con mayorías parlamentarias (en coalición con otros partidos o propias) hacen que la producción legislativa sea dominada por el Poder Ejecutivo (Chasquetti, 2007; Chasquetti y Guedes, 2011; Buquet y Luján, 2011; López Cariboni y Moraes, 2014) y el 2015 no fue la excepción.

Las Tablas 2 y 3 muestran la legislación iniciada y aprobada (respectivamente) en el primer año de todos los gobiernos de Uruguay desde 1985 hasta 2015, discriminando la legislación según haya sido iniciada por el Poder Ejecutivo o por el Poder Legislativo. Observar la legislación que se aprueba al comienzo de los mandatos es importante porque en Uruguay las principales reformas se suelen procesar en los primeros años

11 La Constitución establece que el Poder Ejecutivo tiene iniciativa privativa en materia de gastos, de creación y supresión de empleos públicos y en el otorgamiento y aumentos de retiros, pensiones y dotaciones pecuniarias. Asimismo, el Poder Ejecutivo tiene iniciativa privativa en proyectos de ley con "declaratoria de urgente consideración", proyectos que deben ser considerados por el Poder Legislativo en períodos acotados, de lo contrario se convierten en ley. 
de gestión de los gobiernos (Chasquetti, 2014). Asimismo, en el primer año de mandato los ejecutivos presentan el proyecto de Ley de Presupuesto, la ley más importante de cualquier gobierno, no solo porque contiene la asignación del gasto público para el quinquenio, sino porque estas leyes suelen tener las principales reformas y acciones de política pública que cada gobierno se propone implementar hasta el final de su mandato.

En 2015 el PE envió 106 proyectos de ley al Parlamento, lo que representa el 30\% de la legislación iniciada (Tabla 2). Si se observa le legislación sancionada por el Parlamento, el $90 \%$ de las leyes correspondieron a proyectos de ley iniciados por el Poder Ejecutivo (Tabla 3). En términos absolutos esto representa uno de los años de menor producción legislativa para el PE, tanto en inicio de legislación como en legislación sancionada -el segundo después de 1995-. No obstante, 2015 muestra la misma tendencia que los primeros años de los mandatos anteriores: la mayoría de la legislación que sanciona el Parlamento corresponde a la agenda del Presidente y sus ministros. En este sentido, 2015 fue "extremo", pues casi toda la legislación que pasó al Parlamento (43 de las 48 leyes sancionadas) fue iniciada por el Ejecutivo. La Tabla 4 muestra la tasa de efectividad (número de proyectos iniciados sobre número de leyes) del Ejecutivo y del Parlamento en el primer año de los gobiernos posdictadura. 2015 fue el año de mayor efectividad del Ejecutivo junto con 2005 (el primer año del primer gobierno de Tabaré Vázquez). En ambos, el Ejecutivo logró pasar el $41 \%$ de sus proyectos. En términos de decretos, 2015 también fue el año en el que el Ejecutivo pasó menos decretos en comparación con igual período de los gobiernos anteriores (Tabla 5).

Pese a la menor cantidad de leyes y decretos que el PE pasó en 2015, en términos sustantivos, fue efectivo para hacer avanzar la mayoría de las políticas anunciadas el 1 de marzo, varias de las cuales están contenidas en la Ley de Presupuesto Nacional (Tabla 6). Sin embargo, en educación, área de particular relevancia para el gobierno, se registraron avances escasos en relación con las transformaciones prometidas por Vázquez.

Tabla 2. Proyectos de ley presentados en primeros años de mandato según poder que inició la legislación

\begin{tabular}{|c|c|c|c|c|c|c|}
\hline & \multicolumn{2}{|c|}{ Poder Ejecutivo } & \multicolumn{2}{|c|}{ Poder Legislativo } & \multicolumn{2}{|c|}{ Total } \\
\hline & $\mathrm{N}^{\mathrm{o}}$ & Porcentaje & $\mathrm{N}^{\mathrm{o}}$ & Porcentaje & $\mathrm{N}^{\mathrm{o}}$ & Porcentaje \\
\hline 1985 & 110 & 26 & 311 & 74 & 421 & 100 \\
\hline 1990 & 149 & 38 & 242 & 62 & 391 & 100 \\
\hline 1995 & 100 & 31 & 223 & 69 & 323 & 100 \\
\hline 2000 & 167 & 35 & 306 & 65 & 473 & 100 \\
\hline 2005 & 155 & 34 & 294 & 66 & 449 & 100 \\
\hline 2010 & 179 & 45 & 218 & 55 & 397 & 100 \\
\hline 2015 & 106 & 30 & 245 & 70 & 351 & 100 \\
\hline
\end{tabular}

Fuente: Elaboración a base de datos de Chasquetti y Guedes (2011) y al Sistema de Información Parlamentaria del Parlamento Uruguayo. 
Tabla 3. Leyes sancionadas en primeros años de mandato según Poder que inició la legislación

\begin{tabular}{|c|c|c|c|c|c|c|}
\hline & \multicolumn{2}{|c|}{ Poder Ejecutivo } & \multicolumn{2}{|c|}{ Poder Legislativo } & \multicolumn{2}{|c|}{ Total } \\
\hline & $\mathrm{N}^{\mathrm{o}}$ & Porcentaje & $\mathrm{N}^{\mathrm{o}}$ & Porcentaje & $\mathrm{N}^{\mathrm{o}}$ & Porcentaje \\
\hline 1985 & 36 & 56 & 28 & 44 & 64 & 100 \\
\hline 1990 & 46 & 72 & 18 & 28 & 64 & 100 \\
\hline 1995 & 33 & 76 & 10 & 24 & 43 & 100 \\
\hline 2000 & 47 & 75 & 16 & 25 & 63 & 100 \\
\hline 2005 & 63 & 69 & 28 & 31 & 91 & 100 \\
\hline 2010 & 60 & 77 & 18 & 23 & 78 & 100 \\
\hline 2015 & 43 & 90 & 5 & 10 & 48 & 100 \\
\hline
\end{tabular}

Fuente: Elaboración a base de datos de Chasquetti y Guedes (2011) y al Sistema de Información Parlamentaria del Parlamento Uruguayo.

Tabla 4. Tasa de eficiencia en la producción legislativa por poderes (proyectos/leyes) en primer año de los gobiernos posdictadura (en porcentaje)

\begin{tabular}{lccc}
\hline & Poder Ejecutivo & Poder Legislativo & Total \\
\hline 1985 & 33 & 9 & 15 \\
1990 & 31 & 7 & 16 \\
1995 & 33 & 4 & 13 \\
2000 & 28 & 5 & 13 \\
2005 & 41 & 10 & 20 \\
2010 & 34 & 8 & 20 \\
2015 & 41 & 2 & 14 \\
\hline
\end{tabular}

Fuente: Elaboración a base de datos de Tablas 2 y 3.

Tabla 5. Cantidad de decretos en primer año de los gobiernos (año 2000 en adelante)

\begin{tabular}{lc}
\hline Año & Número de decretos \\
\hline 2000 & 368 \\
2005 & 521 \\
2010 & 429 \\
2015 & 290 \\
\hline
\end{tabular}

Fuente: Elaboración a base de datos de Buquet y Luján 2011 y sitio web de Presidencia de la República. 
Tabla 6. Avances en la agenda del gobierno durante el año 2015

\begin{tabular}{|c|c|}
\hline \multicolumn{2}{|c|}{ Políticas prioritarias para el PE } \\
\hline $\begin{array}{l}\text { Descentralización territorial (creación de nuevos } \\
\text { municipios) }\end{array}$ & Ley $N^{\circ} 19.319$ \\
\hline $\begin{array}{l}\text { Transformación de la Fiscalía Nacional en servicio } \\
\text { descentralizado }\end{array}$ & Ley $\mathrm{N}^{\mathrm{o}} 19.334$ \\
\hline $\begin{array}{l}\text { Creación de la Secretaría Nacional de Ambiente, } \\
\text { Agua y Cambio Climático }\end{array}$ & Art. 33 Ley N 19.355 (Presupuesto Nacional) \\
\hline $\begin{array}{l}\text { Creación de la Secretaría Nacional de Ciencia } \\
\text { y Tecnología }\end{array}$ & Art. 34 Ley No 19.355 (Presupuesto Nacional) \\
\hline Gobierno Electrónico & $\begin{array}{l}\text { Arts. } 75 \text { a } 85 \text {, Ley No } 19.355 \text { (Presupuesto Nacional, } \\
\text { programa "Trámites en Línea" y programa } \\
\text { "Gobierno Electrónico") }\end{array}$ \\
\hline Secretaría Nacional de Deporte & $\begin{array}{l}\text { Ley N } N^{\circ} 19.331 \text { y Art. } 86 \text { a 110, Ley No } 19.355 \\
\text { (Presupuesto Nacional) }\end{array}$ \\
\hline Creación del Sistema Nacional de Cuidados & $\begin{array}{l}\text { Ley N } 19.353 \text { y Arts. } 519 \text { a } 521 \text { Ley No } 19.355 \\
\text { (Presupuesto Nacional) }\end{array}$ \\
\hline $\begin{array}{l}\text { Incremento en servicios del Sistema Nacional } \\
\text { Integrado de Salud }\end{array}$ & Decreto 364/015 \\
\hline $\begin{array}{l}\text { Plan de Inclusión Digital de los jubilados y } \\
\text { pensionistas (entrega de tablets gratuitas) }\end{array}$ & Decreto 130/015 (Creación del Plan Ibirapitá) \\
\hline Institucionalización del Plan Juntos & $\begin{array}{l}\text { Art. } 480 \text { a 487, Ley N } \mathrm{N}^{\circ} 19.355 \text { (Presupuesto } \\
\text { Nacional) }\end{array}$ \\
\hline $\begin{array}{l}\text { Restitución del Impuesto de Primaria al sector } \\
\text { rural }\end{array}$ & Ley $\mathrm{N}^{\mathrm{o}} 19.633$ \\
\hline $\begin{array}{l}\text { Modificaciones a la liquidación del Impuesto a } \\
\text { la Renta de las Personas Físicas }\end{array}$ & Ley $\mathrm{N}^{\mathrm{o}} 19.321$ \\
\hline Inversión en infraestructura & $\begin{array}{l}\text { Plan Quinquenal de Infraestructura (asignación } \\
\text { de prioridades de inversión y asignación de gasto, } \\
\text { Ley N } \mathrm{N}^{\mathrm{T}} 19.355 \text {, Presupuesto Nacional) }\end{array}$ \\
\hline Institucionalización del FONDES & Ley $\mathrm{N}^{\mathrm{o}} 19.337$ \\
\hline Asignación del 6\% del PBI a la educación & Ley N N 19.355 (Presupuesto Nacional) \\
\hline Transformaciones curriculares en educación & Pendiente \\
\hline Creación del Sistema Nacional de Competitividad & $\begin{array}{l}\text { Proyecto de ley presentado el 9/03/2015, en } \\
\text { trámite }\end{array}$ \\
\hline
\end{tabular}

Fuente: Elaboración a base de prioridades anunciadas por Tabaré Vázquez en cadena nacional el 1 de marzo de 2015 y revisión de normativa (proyectos de ley, leyes y decretos).

El debate se centró en aspectos presupuestales que generaron intensas movilizaciones de los sindicatos docentes (ver abajo). Este hecho generó dos crisis institucionales: en primer lugar el decreto de esencialidad firmado por Vázquez para obligar a los docentes a asistir a las aulas (ver abajo), y en segundo lugar, la destitución y renuncia de los dos principales cuadros técnicos del Ministerio de Educación y Cultura: el Director Nacional 
de Educación, Juan Pedro Mir, y el subsecretario del Ministerio, Fernando Filgueira. Esta última crisis se precipitó cuando Mir señaló, en una reunión política, que se estaba muy lejos de cambiar el ADN de la educación y que no se sabía cómo se alcanzarían las metas en los indicadores educativos anunciadas por Vázquez el 1 de marzo. Ante estos dichos Vázquez solicitó a la ministra de Educación y Cultura María Julia Muñoz que le pidiera la renuncia a Mir, lo que se concretó unos días más tarde y trajo consigo la renuncia de Filgueira quien decidió dar un paso al costado en solidaridad con Mir.

Los malos indicadores educativos, en particular las cifras de inclusión y deserción de estudiantes en la educación media, representan un núcleo duro de roer para la izquierda, sobre todo si se tiene en cuenta el significativo aumento de gasto público en educación de los gobiernos del FA. La dificultad para modificar la política educativa deviene, por un lado, de una "herencia institucional" dada por la escasa injerencia que tiene el Ministerio de Educación y Cultura en esta área debido a que sobre ella decide un ente autónomo (la Administración Nacional de Educación Pública-ANEP) y cuatro consejos descentrados. ${ }^{12}$ Por otro lado, los intentos de modificar las políticas educativas en Uruguay en la posdictadura han encontrado siempre la resistencia de los sindicatos docentes que cuentan con amplio poder de organización y vínculos sólidos con el FA (Pribble, 2013). En este sentido, cuando el FA llegó al gobierno, promovió transformaciones institucionales que no solo no modificaron la división de las agencias rectoras de la educación y la incidencia de los sindicatos en la política educativa, sino que la reprodujeron. ${ }^{13}$ Tanto Filgueira como Mir eran férreos defensores de la transformación curricular y de promover una mayor coordinación de las políticas educativas y se enfrentaron repetidas veces con los sindicatos docentes y con las autoridades de la ANEP.

\section{PODER LEGISLATIVO}

Las elecciones nacionales de 2014 dejaron un Parlamento donde el FA vuelve a tener mayorías parlamentarias ajustadas como en el período anterior (50 bancas en 99 en la Cámara de Diputados y 16 de 31 en el Senado). En la oposición, en tanto, aumentó la fragmentación aunque el principal partido sigue siendo el PN: cuenta con 32 diputados y 10 senadores (gana dos diputados y pierde un senador respecto del período anterior). El PC, en tanto, tiene 13 diputados y cuatro senadores, siendo el partido que más redujo su bancada en relación con el período 2010-2015 cuando tenía 17 diputados y cinco senadores. Entre los partidos chicos, el Partido Independiente, un partido de centro, pasó de tener solo dos diputados en el Parlamento anterior a tener tres diputados y un senador en la actualidad, en tanto, por primera vez, Unidad Popular, un partido de izquierda radical escindido del FA, obtuvo una banca en la Cámara de Diputados.

12 Esto no solo dificulta la incidencia del PE, sino también la coordinación de políticas que permitan un pasaje más fluido de los estudiantes entre ciclos.

13 En la Ley General de Educación sancionada en 2008 se creó un nuevo concejo desconcentrado de la ANEP y se institucionalizó la presencia de los sindicatos docentes en ellos, habilitando a que un consejero sea representante de los docentes. 
Por otro lado, el Parlamento electo para el período 2015-2020 es el más feminizado de la historia con 18,2\% de legisladoras. La aplicación por primera vez de la llamada Ley de Cuotas tuvo sus mayores efectos en el Senado, donde las legisladoras pasaron de representar el 12,9\% de los miembros de la Cámara Alta a ser el 25,8\%.

Pese a que el partido de gobierno volvió a contar con mayorías parlamentarias propias, como se dijo, la actual bancada del FA está más a la izquierda del Presidente que en los períodos anteriores debido a la cantidad de bancas que controlan los sectores del expresidente (y actual senador) José Mujica y del actual vicepresidente de la República, Raúl Sendic, en relación con las bancas del ala moderada que lidera Danilo Astori. Asimismo, la actual bancada del FA cuenta con otros grupos menores como Casa Grande y la Liga Federal que, aunque no se ubican en ninguno de los dos grandes grupos, suelen tener posiciones más cercanas a las dos fracciones mayores del ala radical del FA. Si bien el FA suele ser un partido disciplinado en el Parlamento, en la legislatura actual se produjeron algunas disidencias que generaron preocupación a la interna del gobierno. En la votación de la Ley de Presupuesto tres legisladores FA (dos de la fracción Liga Federal y Víctor Semproni de la lista 6009) se negaron a votar un artículo que suprimía vacantes en las Fuerzas Armadas. Si bien no es la primera vez que un legislador frenteamplista se indisciplina respecto de la posición mayoritaria, y este puede ser nuevamente un caso aislado como los anteriores, puso en alerta al gobierno y al propio partido por la fragilidad que podría tener la bancada frenteamplista en el futuro ante mayorías tan ajustadas.

En términos de la actividad del Parlamento, como se vio en las Tablas 2 a 4, la producción legislativa estuvo dominada por el PE: durante 2015 el Parlamento solo pasó 5 leyes cuyos proyectos fueron iniciativa de miembros de alguna de las Cámaras, las otras 43 leyes aprobadas fueron iniciadas por el Ejecutivo. Sin embargo, las actividades que otorgaron mayor visibilidad pública al Parlamento se concentraron en las tareas de fiscalización. En especial, en los trabajos de la comisión investigadora creada en el Senado, a pedido de la oposición, respecto de la gestión de ANCAP, la petrolera estatal.

El Parlamento uruguayo dispone de varios mecanismos para controlar al PE. Los pedidos de informes, los llamados a sala y las interpelaciones son los más utilizados en ese orden de frecuencia por el Legislativo (ver por ejemplo Chasquetti y Guedes, 2011). En 2015, sin embargo, a las actividades usuales de fiscalización se le sumó la creación de una comisión investigadora, la primera en la era de los gobiernos del FA. Aunque la creación de comisiones investigadoras es una de las potestades del Parlamento, su creación no es usual porque para ello se requiere mayoría parlamentaria y porque la creación de un ámbito de este tipo presume la existencia de actividades ilícitas.

La creación de la comisión investigadora sobre ANCAP surgió a partir de los balances de la petrolera que mostraban un déficit millonario contraído durante la administración de Raúl Sendic al frente del ente (actual vicepresidente de la República y eventual candidato del FA en 2019, fue presidente de ANCAP entre 2008 y 2009, y entre 2010 y 2013). En este contexto, la oposición comenzó a presionar para crear una comisión que investigara presuntos hechos de corrupción. Luego de idas y vueltas, la bancada del FA concedió a la oposición los votos para crear la comisión, en el entendido de que no existía delito ni 
información que ocultar. Las críticas concernientes a mala gestión y posible corrupción en ANCAP resonaron durante todo el segundo semestre y cobraron aún más relevancia cuando a finales del año el gobierno se vio forzado a impulsar una ley para capitalizar a la empresa por US\$ 600 millones ante su crítica situación financiera. Este proceso, se suma a cuestionamientos similares realizados por la oposición a la gestión de PLUNA en la administración Mujica -la exaerolínea uruguaya donde el Estado tenía una parte de las acciones- que valieron la renuncia del ministro de Economía de Mujica. Aunque en este último caso no se llegó a crear una comisión investigadora, la crítica de la oposición fue igualmente visible en los medios. Ambos hechos han contribuido a poner en cuestión ante la ciudadanía la capacidad de gestión del FA al frente de la administración y han nutrido la agenda de la oposición.

\section{CONFLICTO Y PROTESTA SOCIAL: GOBIERNO Y ACTORES SOCIALES ENFRENTADOS POR DISTRIBUCIÓN}

El 2015 fue el de mayor movilización social que registró un gobierno del FA ${ }^{14}$ y tuvo en el centro del conflicto las negociaciones de la Ley de Presupuesto y las pautas que el gobierno propuso para las rondas de negociación de los Consejos de Salarios. El gobierno ante un escenario económico menos favorable tenía la aspiración de controlar la inflación y el déficit fiscal. En consecuencia, el proyecto de Ley de Presupuesto del PE retardaba el aumento del gasto público y las pautas de los Consejos de Salarios moderaban los incrementos salariales respecto de los gobiernos previos del FA (Rodríguez et al., 2015).

Si se observa la conflictividad por sectores, el de la educación pública fue el más conflictivo (explica el 33\%), seguido por la construcción (28\%) y la administración pública (20\%). La mayor conflictividad también se vio reflejada en el aumento de paros generales: en 2015 se realizaron cinco, uno de ellos de 24 horas. Por otro lado, en un contexto de discusión presupuestal y salarial, donde aún se registran niveles de desempleo bajos para el promedio histórico, casi el 70\% de la conflictividad tuvo como motivo temas salariales (Ibídem).

De todos los conflictos también el más visible fue el de la educación pública. El PE propuso un incremento gradual del gasto público en educación, con incrementos escalonados en los salarios de los docentes, hasta alcanzar la meta del 6\% del PBI en el 2020.

Los gremios docentes no aceptaron esta propuesta exigiendo que el $6 \%$ se cumpliera desde el primer año de vigencia del nuevo presupuesto. Incluso anticipando los contenidos del mensaje presupuestal del Ejecutivo, iniciaron los paros antes de que el proyecto de ley ingresara al Parlamento.

El punto más álgido del conflicto se produjo a fines de agosto cuando el gobierno y los gremios de la enseñanza (primaria y secundaria) firmaron un preacuerdo salarial en el

14 En comparación con los primeros años de mandato de los gobiernos posdictadura, 2015 solo es superado por los años 1995 y 2000 (Rodríguez et al., 2015). 
Gráfico 3. Evolución del Índice de Conflictividad Laboral 2005-2015

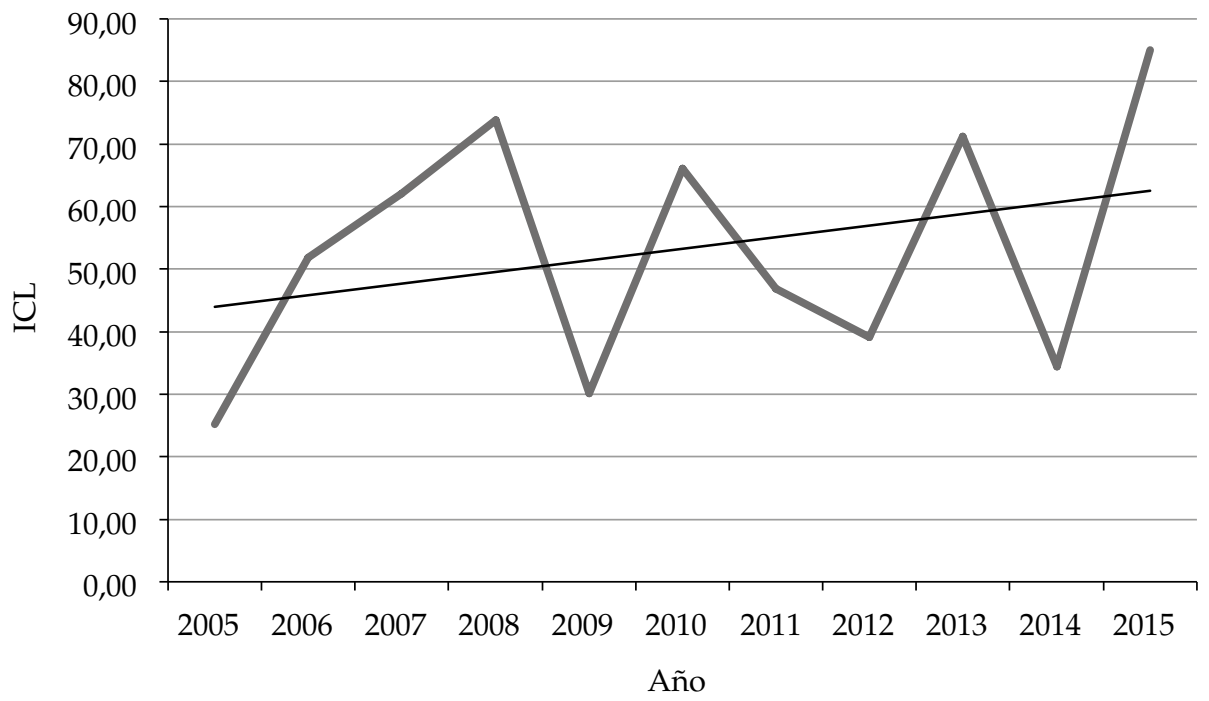

Fuente: Rodríguez et al. 2015.

que el primero se comprometía a mejorar las pautas salariales sujeto al compromiso, por parte de los docentes, de mejorar la calidad de los procesos educativos y no parar sus actividades por reclamos salariales futuros. La firma del preacuerdo hizo pensar a las autoridades que el conflicto se desactivaría, pero los docentes siguieron movilizados, las bases sindicales evaluaron la nueva propuesta como insuficiente, decidieron continuar con los paros y acusaron al gobierno de "neoliberal".

Ante la "pulseada" de los sindicatos, y debido a que el gobierno entendía que la propuesta de aumento salarial era "la mejor" de todo el sector público y lo máximo que el gobierno podía otorgar, el Presidente, en acuerdo con la ministra de Educación y Cultura, decretó la esencialidad de los servicios de la educación primaria, secundaria y técnico-profesional. ${ }^{15}$ La medida obligaba a los docentes a concurrir a las aulas a riesgo de ser despedidos. $\mathrm{Al}$ anunciar la medida la ministra Muñoz señaló que la esencialidad se justificaba en la necesidad de "garantizar la asistencia a clase de todos los niños, niñas y adolescentes del país", en especial estaba destinada a proteger a los estudiantes de hogares más vulnerables que eran los que más veían "trastocada su vida cotidiana" por la suspensión de clases. 16

Aunque antes de asumir Vázquez había anunciado que no descartaba declarar la esencialidad en la educación en caso de suspensiones continuas de las clases, el decreto de esencialidad cayó por sorpresa y desató la furia de los sindicatos de la enseñanza. Los gremios decidieron no acatar la medida y acusaron al gobierno de represor "pachequista", 
en alusión al gobierno del Presidente colorado Jorge Pacheco Areco (1967-1972) quien había decretado medidas de excepción ante las movilizaciones sociales que se produjeron durante su gobierno. La central única de trabajadores (PIT-CNT) también calificó a la esencialidad como inapropiada, anunció gestiones ante la OIT y convocó a un paro general parcial el 22 de agosto.

El Frente Amplio, lejos de subordinarse a la voluntad del Presidente criticó la medida-sobre todo algunos sectores como el que lidera el expresidente José Mujica- e intentó mediar entre el gobierno y los gremios de la educación. De hecho, el decreto de esencialidad puso a prueba al FA en su relacionamiento con los sindicatos, las bases sociales más importantes del partido. Si bien en otros momentos de la gestión de gobierno del FA habían existido diferencias entre gobierno y sindicatos, y no era la primera vez que un gobierno de la izquierda decretaba la esencialidad de un servicio del Estado, en las ocasiones anteriores esta medida fue tomada en servicios donde la interrupción de actividades implicaba riesgo de vida o sanitario para la población. Por otro lado, la virulencia de la protesta sindical también ponía al FA en tensión frente a la ciudadanía. En especial, con sectores de clases medias y populares que envían a sus hijos a la educación pública, para quienes la suspensión de las clases no solo generaba un perjuicio en términos educativos, sino también de cuidados -y en algunos casos de alimentación.

Aunque la medida de esencialidad estuvo vigente varios días, en los hechos no se aplicó, ya que con despidos masivos no habría forma de retomar las clases de manera normal. Finalmente, luego de mediaciones realizadas por el PIT-CNT y el FA la esencialidad se levantó y las clases se retomaron en septiembre aunque los paros continuaron de forma intermitente a lo largo de la discusión del presupuesto en el Parlamento. Durante el tratamiento parlamentario, la bancada de legisladores del FA realizó algunas modificaciones en la asignación del gasto inicial del PE. Destinó más recursos a la educación transfiriendo presupuestos al proyecto para el SNC. No obstante, la Ley de Presupuesto sancionada fue muy similar al proyecto enviado por el PE. En diciembre los sindicatos de primaria y secundaria firmaron un acuerdo con el gobierno por el que el PE se comprometía a mantener el salario real de los docentes y estos a no movilizarse por mejoras salariales (Rodríguez et al., 2015). Los partidos de la oposición, en tanto, criticaron de manera enérgica la Ley de Presupuesto al entender que el gasto previsto no tenía financiamiento y que generaría un déficit fiscal desmedido dado el nuevo contexto económico. ${ }^{17}$

La negociación salarial en la actividad privada también estuvo pautada por la conflictividad. Tanto los sindicatos como las gremiales empresariales realizaron críticas a los lineamientos de negociación propuestos por el gobierno. Para los trabajadores las nuevas pautas salariales eran insuficientes, pues el gobierno moderaba el aumento de los salarios en un contexto que no calificaban de crisis, sino de simple desaceleración. Ante esto, el PIT-CNT planteó que el movimiento de trabajadores no compartía "la idea que subyace en los lineamientos de que solo se puede mejorar la distribución de los ingresos cuando la economía crece significativamente" y que la "variable de 
ajuste" no podía ser el salario de los trabajadores. ${ }^{18}$ Para las cámaras empresariales, en tanto, las pautas salariales eran "preocupantes", ya que la nueva situación nacional e internacional que afrontaban las empresas solo ameritaba el mantenimiento del salario real, pero no incrementos como planteaba el PE. ${ }^{19}$ Pese a las críticas que recibieron los lineamientos salariales y la conflictividad que produjeron, a fines de 2015 culminaron las negociaciones de la mayoría de los convenios que vencían ese año. Aunque aún no existen datos oficiales acerca del resultado de las negociaciones, datos preliminares muestran que el 50\% de los convenios se aprobaron por consenso (entre trabajadores, empresarios y gobierno), ${ }^{20}$ cifra significativamente menor que en las rondas anteriores cuando los convenios por consenso alcanzaron niveles superiores al 75\%.21

Por último, otro de los conflictos que tuvo que afrontar el PE giró en torno a la intención de Uruguay de incorporarse a las negociaciones del acuerdo global de servicios TISA (Trade Services Agreement) que, en caso de concretarse, suponía la apertura del comercio de servicios. El ingreso a las negociaciones se produjo durante el gobierno de Mujica, pero no habían trascendido públicamente. Cuando al comienzo del gobierno de Vázquez las negociaciones por el TISA se hicieron públicas el PIT-CNT se opuso, acusando al gobierno de negociar en secreto. El 16 de junio la central de trabajadores convocó a un paro general parcial bajo la consigna "por mayor presupuesto y no al TISA, que los cambios no se detengan". A la oposición del PIT-CNT se sumó la oposición del FA, que en su Plenario Nacional votó una resolución contraria al TISA por 117 votos en 139.22 Con el partido y los sindicatos en su contra el Presidente decidió la salida de Uruguay del TISA.

Lo anterior muestra los dilemas de economía política que el nuevo escenario económico le plantea al gobierno del Frente Amplio. En este sentido, la experiencia de los gobiernos del FA a lo largo de los ciclos económicos debe inscribirse en el marco de los trabajos que estudian los constreñimientos que tienen los partidos latinoamericanos que asumen con discursos de izquierda/progresistas para gobernar por izquierda en contextos de crisis económicas. Investigaciones como las de Murillo, Oliveros y Vaishnav (2011) y Campello (2014) muestran que los Presidentes electos bajo agendas de izquierda son diferentes a los Presidentes electos bajo promesas liberalizantes. En contextos de crisis los Presidentes electos bajo discursos de izquierda tienen incentivos para "virar" de agenda y correrse a la derecha. En América Latina, una región con escases de capital, el factor que explica el corrimiento hacia la derecha de los Presidentes de izquierda es la marcha de la economía. Cuando la escasez de capital se ve aliviada por el aumento de los precios internacionales de los commodities la probabilidad de observar Presidentes que ejecutan políticas por izquierda aumentan. En cambio, cuando de Salarios"

19 El País, 17 de julio de 2015.

$20 \quad$ La Diaria, 29/1/2016.

21 Ver por ejemplo Senatore y Méndez (2011) e “Informe de la Quinta Ronda del Consejos de Salarios" (MTSS, disponible en: http:/ / www.mtss.gub.uy/documents/11515/7d500820-51a7-426c-bf27-e289785bdf30 ).

22 El País 6/9/2015. 
los precios de los commodities bajan y se produce escasez de capital, los gobiernos de los países latinoamericanos comienzan a estar constreñidos en sus programas por los organismos internacionales y por la necesidad de atraer inversiones extranjeras que no ven con buenos ojos las políticas intervencionistas de los gobiernos de izquierda. Murillo, Oliveros y Vaishnav (2011) anticipan un movimiento pendular en América Latina con ciclos de izquierda y de derecha en función de los contextos económicos.

Campello (2014) señala que en contextos de crisis los gobiernos de izquierda estarán sometidos al dilema de avanzar en las políticas intervencionistas y redistributivas que esperan sus votantes y atraer inversores que esperan políticas promercado. Cuanto mayor sea la dependencia del gobierno del financiamiento de capitales extranjeros, mayores serán sus incentivos a desarrollar una agenda que satisfaga a los inversores. Las motivaciones para virar de agenda son, entonces, estrictamente económicas. No obstante, Campello (2014) señala que el giro hacia una agenda más liberal en los gobiernos de izquierda está limitado por la institucionalización del partido del Presidente..$^{23}$

El tercer gobierno del Frente Amplio parece estar enfrentando el dilema al que aluden Murillo, Oliveros y Vaishnav (2011) y Campello (2014). En un contexto de desaceleración de la economía producto de factores externos, el gobierno se ve enfrentado a las demandas de los sindicatos -que a su vez se han fortalecido por las políticas de los gobiernos del FA- por mayor aumento del gasto social y distribución. No obstante, en una economía que comienza a dejar de crecer las demandas de los sindicatos solo pueden ser satisfechas a costa de aumentar el déficit fiscal y la inflación o gravando más al capital. La primera opción no es viable para una izquierda que intenta mantener los equilibrios macroeconómicos y produciría un aumento de la inflación. La segunda opción, en tanto, podría generar una contracción de la producción y una fuga de capitales -por condiciones menos atractivas para la inversión- agudizando el problema del crecimiento.

La conflictividad como expresión visible del conflicto entre capital y trabajo en un escenario económico contractivo y de la tensión a la que está sometida la relación entre el gobierno del FA y sus bases sociales ha sido en 2015 y será en los próximos años la nueva tónica de la política uruguaya. Este nuevo fenómeno abre un panorama de incertidumbre respecto de la capacidad del FA y del movimiento sindical (PIT-CNT) para articular una nueva relación que no ponga en jaque por un lado la representatividad del movimiento sindical (en tanto defensor de los intereses de la clase trabajadora) y, por otro, la capacidad del gobierno para contener la inflación y asegurar crecimiento.

23 Campello (2014) señala que Presidentes electos bajo agendas liberales no tienen este trade-off. Como su mandato es por liberalizar, no existen razones para pensar que un boom o una crisis de capitales afecte su comportamiento. Los Presidentes neoliberales podrán desarrollar políticas propobres en períodos de crecimiento en mayor medida que en períodos de crisis, no obstante, esas políticas no implicaran renunciar a una agenda liberal sobre el funcionamiento de los mercados. 


\section{CONCLUSIONES}

El FA tuvo el año más difícil en el gobierno desde que asumiera en 2005 por primera vez. En el segundo semestre de 2015 la gestión de Vázquez deterioró su imagen abruptamente y registró los niveles más bajos de evaluación de los últimos 10 años. Mientras que en el primer semestre obtenía evaluaciones positivas cercanas al 50\%, en el segundo estas bajaron al 29\%. ${ }^{24}$ A pesar de que FA ganó en 2014 las elecciones por tercera vez consecutiva con mayorías absolutas en ambas Cámaras del Parlamento, la desaceleración económica, una situación interna más compleja dentro del FA y una oposición renovada y más activa hicieron que este año y los próximos supongan un nuevo reto para la izquierda en el gobierno.

La desaceleración económica y las expectativas negativas sobre el futuro de la economía uruguaya han puesto en tensión al gobierno del FA y a sus bases sociales. Lo enfrentó a los trabajadores del sector público en la definición del presupuesto quinquenal y a los trabajadores privados en la fijación de pautas salariales para la negociación colectiva. La distribución de la carga del ajuste frente al deterioro de los resultados fiscales del gobierno y las presiones inflacionarias hizo de 2015 el año más conflictivo desde que el FA está en el gobierno.

Las tensiones del gobierno de Vázquez con las bases sociales de su partido también se trasladaron hacia adentro del partido. Las elecciones de 2014 dieron como resultado la consolidación y el crecimiento de los sectores más radicales del FA en detrimento de los más moderados. En consecuencia, la bancada de legisladores del partido está más a la izquierda que el Presidente. En particular, la fracción del expresidente José Mujica logró consolidarse como la fracción más importante del FA.

Los partidos de centroderecha en Uruguay, PN y PC, lograron recuperar la iniciativa política luego de la derrota electoral que sufrieron en 2014. Ambos partidos consiguieron que el FA votara por primera vez una comisión investigadora en el Senado para analizar la gestión de la petrolera estatal (ANCAP). Su estrategia se centró en la investigación de la administración de la petrolera por presuntos casos de corrupción, en especial durante la gestión del Raúl Sendic. Este proceso ha puesto también en cuestión ante la ciudadanía la capacidad de gestión del FA al frente de las empresas públicas y de la administración en general, lo que explica también el deterioro de la imagen de la presidencia de Vázquez.

Algunas derrotas electorales sufridas por los gobiernos de izquierda en América Latina han hecho que académicos, analistas y políticos comiencen a hablar del fin de un ciclo. La llamada "marea rosa" parece estar en retroceso en el continente debido a los cambios económicos que produjeron la baja en el precio de los commodities (principal fuente de ingresos de estos países). Estas visiones privilegian el impacto de los factores externos, sin teorizar mucho sobre su funcionamiento, y desconocen su interacción con los procesos

24 Entrevista a Ignacio Zuasnabar, director de Equipos Mori, el 9/10 en Radio Rural. Acceso web: http:// radiorural.uy/por-que-la-popularidad-de-vazquez-bajo-al-29/ (visitado por última vez el 18/2/2016). 
políticos nacionales. El 2015 en Uruguay muestra por un lado el reto que enfrentan los gobiernos de izquierda en la región en un nuevo escenario económico internacional, pero también pone de manifiesto la importancia de los factores políticos, sociales y económicos locales para explicar las características más particulares que adoptan los factores externos en los diferentes países.

\section{BIBLIOGRAFÍA}

Bidegain Ponte, Germán. 2013. “Uruguay: ¿el año bisagra?”. Revista de Ciencia Política 33 (1): 351-374.

Buquet, Daniel y Piñeiro, Rafael. 2014. "La consolidación de un nuevo sistema de partidos en Uruguay". Revista Debates 8 (1): 127-148.

Buquet, Daniel y Luján, Diego. 2011. "El Poder Ejecutivo". En Política en tiempos de Mujica. En busca del rumbo. Informe de Coyuntura No 10, editado por Gerardo Caetano, María Ester Mancebo y Juan Andrés Moraes. Instituto de Ciencia Política, Montevideo: Estuario Editora, 183-193.

Buquet, Daniel y Piñeiro, Rafael. 2010. "De las internas a las municipales: los impactos de las reglas electorales en Uruguay". En Del Cambio a la Continuidad. Ciclo Electoral 2009-2010 en Uruguay, editado por Daniel Buquet y Niki Johnson. Montevideo: Fin de Siglo, 45-70.

BCU. 2015. Informe de Política Monetaria. Cuarto Trimestre 2015, Montevideo: Banco Central del Uruguay.

Campello, Daniela. 2014. "The Politics of Financial Booms and Crises: Evidence From Latin America The Politics of Financial Booms". Comparative Political Studies 47: 260-286.

Canzani, Agustín. 2000. “Mensajes en una botella. Analizando las elecciones 1999-2000". En Elecciones 1999/2000, Instituto de Ciencia Política, Montevideo: Ediciones de la Banda Oriental: 237-264.

Castañeda, Jorge. 2006. "Latin America's Left Turn". Foreign Affairs 85 (3): 28-43.

CINVE 2015. "Balance 2015: Qué pasó y cómo seguirá". Informe de Actividad y Comercio, No 143.

Chasquetti, Daniel. 2014. Parlamento y Carreras Legislativas en Uruguay: Un estudio sobre reglas, partidos y legisladores en las Cámaras. Montevideo: UdelaR.

2007. "Uruguay 2006: éxitos y dilemas del gobierno de izquierda". Revista de Ciencia Política 27 (1): 249-263.

Chasquetti, Daniel y Guedes, Alejandro. 2011. "El primer año legislativo del gobierno de Mujica". En Política en tiempos de Mujica. En busca del rumbo. Informe de Coyuntura $\mathrm{N}^{\mathrm{o}}$ 10, editado por Caetano, Gerardo, María Ester Mancebo y Juan Andrés Moraes. Instituto de Ciencia Política, Montevideo: Estuario Editora, 183-193.

De Armas, Gustavo y Caetano, Gerardo. 2011. “Diez años del Informe de Coyuntura. Del Uruguay de la crisis a las posibilidades y exigencias de desarrollo". En Política en tiempos de Mujica. En busca del rumbo. Informe de Coyuntura $\mathrm{N}^{\circ}$ 10, editado por Gerardo Caetano, María Ester Mancebo y Juan Andrés Moraes. Instituto de Ciencia Política, Montevideo: Estuario Editora, 11-41.

Flores-Macías, Gustavo. 2010. “Statist vs. Pro-Market. Explaining Leftist Governments' Economic Policies en Latin America". Comparative Politics: 413-433.

González, Luis Eduardo y Queirolo, Rosario. 2000. “Elecciones Nacionales del 2004: Posibles Escenarios”. En Elecciones 1999/2000, Instituto de Ciencia Política, Montevideo: Ediciones de la Banda Oriental: 299-321.

Handlin, Samuel. 2012. "Social Protection and the Politicization of Class Cleavages During Latin America's Left Turn". Comparative Political Studies, 46 (12): 1582-1609.

Lanzaro, Jorge. 2015. "Uruguay 2014: elecciones competitivas y partido de izquierda predominante". Revista SAAP 9 (1): 11-41.

2011. "A Social Democratic Government in Latin America". En The Resurgence of the Latin American Left, editado por Levitsky, Steven y Kenneth, Roberts. Baltimore: The Johns Hopkins University Press, 348-374.

Levitsky, Steven y Roberts, Kenneth. 2011. The Resurgence of the Latin American Left. Baltimore: The Johns Hopkins University Press. (Introducción y conclusiones). 
López Cariboni y Queirolo, Rosario. 2015. “Class voting versus economic voting: Explaining electoral behavior before and after the 'Left turn' in Latin America". Ponencia presentada en el $8^{\circ}$ Congreso Latinoamericano de Ciencia Política, ALACIP, 22-24 de julio de 2015.

López Cariboni, Santiago y Moraes, Juan Andrés. 2014. “Uruguay 2013: Un balance preelectoral”. Revista de Ciencia Política 34 (1): 293-313.

Lorenzoni, Miguel y Pérez, Verónica. 2013. "Cambios y continuidades de la izquierda en Uruguay: un análisis a partir de las propuestas programáticas del frente amplio 1971-2009". Revista Uruguaya de Ciencia Política 22 (1): 81-102.

Madrid, Raúl. 2012. The Rise of Ethnic Politics in Latin America. Cambridge: Cambridge University Press.

Moraes, Juan Andrés. 2015. "The Electoral Basis of Ideological Polorization in Latin America". Kellogg Institute for International Studies, Working Paper \# 403.

Murillo, María Victorial, Virginia Oliveros y Milan Vaishnav. 2011. "Economic Constraints and Presidencial Agency". En The Resurgence of the Latin American Left, editado por Levitsky, Steven y Roberts, Kenneth. Baltimore: The Johns Hopkins University Press, 52-70.

Pribble, Jennifer. 2013. Welfare and Party Politics in Latin America, New York: Cambridge University Press. Pribble, Jennifer y Evelyne Huber. 2011. "Social Policy and Redistribution: Chile and Uruguay". En The Resurgence of the Latin American Left, editado por Steven Levitsky y Kenneth Roberts. Baltimore: The Johns Hopkins University Press, 139-161.

Roberts, Kenneth. 2014. Changing Course in Latin America. Party Systems in the Neoliberal Era, New York: Cambridge University Press.

Rodríguez, Juan Manuel, Beatriz Cozzano, Gabriela Mazzuchi, María Eloisa González. 2015. Las relaciones laborales en 2015 y perspectivas para el 2016. Informe diciembre 2015 Instituto de Relaciones Laborales, Facultad de Ciencias Empresariales, Universidad Católica del Uruguay.

Rosenblatt, Fernando. 2006. “El dispar desenlace de la crisis económica en Argentina y Uruguay (20012002): una explicación desde la teoría de las prospectivas". Revista de Ciencia Política 26 (2): 97-119.

Senatore, Luis y Méndez, Gustavo. 2011. “La política salarial en el bienio 2010-2011”. En Política en tiempos de Mujica. En busca del rumbo, editado por Gerardo Caetano, María Ester Mancebo y Juan Andrés Moraes. Informe de Coyuntura $\mathrm{N}^{\circ}$ 10, Instituto de Ciencia Política, Montevideo: Estuario Editora, 113-123.

Weyland, Kurt. 2009. "The Rise of Latin America's Two Lefts: Insights from Rentier State Theory". Comparative Politics 41 (2): 145-164.

Yaffé, Jaime. 2005. Al centro y adentro. La renovación de la izquierda y el triunfo del Frente Amplio en Uruguay. Montevideo: Linardi y Risso.

Verónica Pérez es candidata a Doctora en Ciencia Política de la Universidad Torcuato Di Tella (Argentina) y becaria de la Agencia Nacional de Investigación e Innovación (ANII) de Uruguay. E-mail: veroperezbentancur@gmail.com.

Rafael Piñeiro Rodríguez es Profesor Asistente del Departamento de Ciencias Sociales y Políticas de la Universidad Católica del Uruguay. E-mail: rafael.pineiro@ucu.edu.uy. 
